\title{
Effect of volume of practice in children with probable Developmental Coordination Disorder
}

\section{Efeito do volume da prática por crianças com provável Transtorno do Desenvolvimento da Coordenação}

Leonardo Soares de Carvalho ${ }^{1}$

(D) https://orcid.org/0000-0002-8336-6520

Camila Sant Ana Crancianinov ${ }^{1}$

(D) https://orcid.org/0000-0002-3295-092X

Daniel Traina Gama²

(D) https://orcid.org/0000-0003-3984-326X

Cynthia Yukiko Hiraga ${ }^{1}$

(D) https://orcid.org/0000-0002-4209-7598
Abstract - Children with Developmental Coordination Disorder (DCD) demonstrate a slower and more gradual ability to acquire and learn motor skills with practice. One question then is whether a higher volume of practice for these children could match the performance of children with typical development (TD). The present study aims to examine the effects of a higher volume of practice by children with probable DCD (pDCD) in relation to a lower volume of practice by children with TD. The MABC- 2 was used to identify the participants' level of motor difficulty and set the composition of the groups. Two active video games (Nintendo Wii) were used for the practice. Each group was composed of eight participants, paired up by gender and age, $\mathrm{TD}(\mathrm{M}=111.87$ months; $\mathrm{SD}=4.05)$ and $\mathrm{pDCD}(\mathrm{M}=115.87$ months; $\mathrm{SD}=4.96$ ). The TD group participated in seven practice sessions and the $\mathrm{pDCD}$ group participated in eleven sessions. Results regarding performance on Wii console games showed significant improvement from the first day of practice to the last day in both groups ( $\mathrm{pDCD}$ and TD). A higher volume of practice for children with $\mathrm{pDCD}$ compared to their TD peers helped to increase the performance of the former group. Therefore, the $\mathrm{pDCD}$ group achieved a performance similar to the TD group in both practiced games.

Key words: Developmental coordination disorder; Practice; Virtual reality.

Resumo - Crianças com Transtorno do Desenvolvimento da Coordenação (TDC) demonstram capacidade mais lenta e gradual para adquirir e aprender habilidades motoras com a prática. Uma questão então é se uma prática com maior volume para essas crianças poderia igualar o desempenho em relação às crianças com desenvolvimento típico (DT). O presente estudo teve como objetivo examinar o efeito do maior volume de prática por crianças com provável TDC (pTDC) em relação ao menor volume de prática por crianças com DT. A bateria de testes $M A B C-2$ foi utilizada para identificar o nivel de dificuldade motora dos participantes e compor os grupos. Dois jogos de videogame ativo (Nintendo Wii) foram utilizados para as sessões de prática. Cada grupo foi composto por oito participantes, pareados em gênero e idade, $D T(M=111.87$ meses; $D P=4.05)$ e $p T D C(M=115.87$ meses; $D P=4.96)$. O grupo DT participou de sete sessões de prática e o grupo pTDC participou de onze sessóes de prática. Os resultados referentes ao desempenho nos jogos do console Wii apresentaram melhora significativa do primeiro para o último dia em ambos os grupos de prática (rTDC e DT). Um maior volume de prática para as crianças com $p T D C$ em relação aos seus pares com DT auxiliou no aumento do desempen ho desse grupo. Portanto, o grupo pTDC alcançou desempenho similar ao grupo DT em ambos os jogos praticados.

Palavras-chave: Prática; Realidade virtual; Transtorno do desenvolvimento da coordenação.
1 Universidade Estadual Paulista Júlio de Mesquita Filho. Rio Claro, SP. Brasil

2 Universidade Federal da Grande Dourados. Dourados, MS. Brasil.

Received: March 06, 2020 Accepted: May 18, 2020

How to cite this article Carvalho LS, Crancianinov CSA, Gama DT, Hiraga CY. Effect of volume of practice in children with probable Development Coordination Disorder. Rev Bras Cineantropom Desempenho Hum 2020, 22:e72028. DOl: http://dx.doi. org/10.1590/1980-0037.2020v22e72028

Copyright: This work is licensed under a Creative Commons Attribution 4.0 International License. 


\section{INTRODUCTION}

Difficulties in basic motor coordination in childhood can characterize Developmental Coordination Disorder (DCD). Children with DCD, as reported by their parents ${ }^{1}$, suffer from a lack of minimal motor competence to successfully perform household and school tasks ${ }^{2}$, as expected for their age. In general, these children are introverted and consider themselves less competent in the physical and social spheres ${ }^{3}$. Their low performance in the motor task may be partly the result of a high level of anxiety and stress $^{4,5}$. There are reports in the literature that children with DCD have deficits related to perception, as well as in the planning of motor action ${ }^{6}$. Despite the numerous studies about DCD, the etiology of this disorder remains unknown.

Intervention programs for DCD have been widely investigated ${ }^{7}$. Interventions based on the practice of motor skills in children with DCD generally show improvements in practiced or trained skills ${ }^{8}$. Recently, approaches to motor practices based on active video game technologies that simulate a real environment have been used in children with DCD. These active video games provide simulated environments with the possibility of manipulation of virtual objects that creates a perception of reality ${ }^{9}$. As they are more than a physical activity program that requires metabolic expenditure, active video games also require perceptual-motor integration, decision making, anticipation capacity, body balance and motor coordina$\operatorname{tion}^{10}$. The practice results based on active video games like those of the Wii console are promising, as they demonstrate improvements over the practice sessions in the performance of children with both typical development (TD) and $\mathrm{DCD}^{11}$. However, children with DCD do not reach the same level of performance as children with $\mathrm{TD}^{12}$.

Experimental practice designs comparing both groups are limited to several sessions that are equivalent, in the number of practice sessions, for both groups ( $\mathrm{pDCD}$ and TD). The first hypothesis to be tested in the present study is that the practice based on Wii console games will favor sensorimotor experiences with the potential to alter the performance of children with pDCD in the games. This hypothesis is based on previous studies and seeks confirmation that children with $\mathrm{pDCD}$ have the potential to acquire motor skills as a function of practice and experience, albeit with lower performance than children with TD. The second hypothesis, and of greater relevance in this study, is that the provision of a higher volume of practice (i.e., more sessions) to children with $\mathrm{pDCD}$ in relation to their peers with TD will favor their motor performance in order to match the performances of both groups.

This study proposes to examine the effect of gaming practice on the performance of children with $\mathrm{pDCD}$. In particular, it investigates whether a higher volume of practice by children with $\mathrm{pDCD}$, in relation to a lower volume of practice by children with TD, can make the performances of the groups equal. 


\section{METHODS}

\section{Participants}

Eight children classified as pDCD aged between 9 and 10 years participated in this study. In addition, eight children with TD, paired in age and gender, formed the control group for comparison purposes. The parents or guardians of the participants signed the Informed Consent Form, duly approved by the Human Research Ethics Committee of the Biosciences Institute at São Paulo State University.

The denomination $\mathrm{pDCD}$ was adopted, based on the performance of the Movement Assessment Battery for Children-213 (MABC-2). The score below or in the 5 th percentile on the MABC- 2 were classified as $\mathrm{pDCD}$. The term DCD was not adopted, as in the present study, the identification of the children's motor skills occurred through the results of a field test administered by trained professionals. The procedures in the present study do not consider all the criteria described in the Diagnostic and Statistical Manual of Mental Disorders ${ }^{14}$ for DCD. Thus, it was not possible to determine, for instance, whether the motor difficulties of children were affecting their daily activities (Criterion B).

Although MABC-2 is not a gold standard test for diagnosing children with and without DCD, it does provide a reasonable view of the functioning of each child's basic motor skills. In addition, children with comorbidities such as attention deficit disorder, autism spectrum disorder, any neurological diagnosis, intellectual disability assessed by the school staff at the beginning of the school year were not included in the sample. This means that any children with a special academic requirement or who attend a specialized center for further education were not included in the sample.

The children selected to compose the group with typical development (TD, i.e., without the $\mathrm{pDCD}$ ) were those who had a total score above the 25 th percentile. Weight and height measurements were collected to calculate the body mass index (BMI) in order to select children with close BMIs between the two groups, as shown in Table 1.

Table 1. Characterization for the $\mathrm{PDCD}$ and TD groups

\begin{tabular}{lcc}
\hline & pDCD & TD \\
\hline Male (N) & 05 & 05 \\
Female (N) & 03 & 03 \\
Age (months) (M, S.D.) & $115.87(4.96)$ & $111.87(4.05)$ \\
BMI (kg/m²) (M, S.D.) & $16.63(4.69)$ & $16.5(1.6)$ \\
MD Total Score (M, S.D.) & $5.5(1.92)$ & $10.5(2.78)$ \\
AC Total Score (M, S.D.) & $6(2.39)$ & $11.88(3.27)$ \\
BA Total Score (M, S.D.) & $4(1.69)$ & $9,5(3.25)$ \\
Total Component (M, S.D.) & $45.75(10.15)$ & $81.5(12.62)$ \\
Total Percentile (M, S.D.) & $2.75(1.96)$ & $51.36(20.64)$ \\
\hline
\end{tabular}

MD - Manual dexterity; AC - Aiming and Catching; BA - Balance; pDCD - probable Development Coordination Disorder; TD - Typical Development. N - number; M - Mean; S.D. - Standard deviation values in parentheses. 


\section{Materials}

The MABC-2 was used to identify children with $\mathrm{pDCD}$ and TD. The MABC-2 consists of eight tasks that require skills in the components of manual dexterity, aiming and catching, and dynamic and static balance. A stadiometer and a body scale (Model Tanita) were used to calculate the body mass index (BMI). A Wii console (MotionPlus) along with Wii Sports and Wii Sports Resort compact discs were selected for the gaming practice of Tennis and Archery, respectively. An LCD television set was used to project the games of the Wii console.

\section{Procedures}

Initially, participants underwent collections of measurements of weight and height to calculate the body mass index (BMI). The following formula calculates BMI: Weight / Height ${ }^{2}$. Children underwent MABC-2 on the same day that the weight and height data were collected. The MABC-2 identified the participants' level of motor difficulty and compose the group participants. Each child was assessed individually in a safe and appropriate room. The performance of MABC-2 tasks takes into account the execution time or the number of correct executions. The collected data of each participant were converted into scores according to the instructions in the MABC-2 manual ${ }^{14}$.

After the assessment, the practice sessions with the Wii console games were administered in seven days for children in the TD group. For children with pDCD, sessions were administered over 11 days. Children from both groups played games with a frequency of up to twice a week. Each practice session lasted approximately 40 minutes. Wii games were administered in each practice session, namely: Wii Sports (Tennis training mode - 20 attempts; Tennis game mode - 10 minutes), and Wii Sports Resort (Archery - 5 games). The Tennis game mode was performed only for the motivational purposes of the participants, and therefore their scores were not recorded for further analysis. The scores in each game during each practice session were recorded for analyses.

The choice of Tennis on the Nintendo Wii for practice occurred because this game stimulates, according to Deutsch and collaborators ${ }^{15}$, the muscle tone necessary for postural maintenance during the performance of rotational movements of the trunk and upper limbs, in addition to requiring the participation of haptic, auditory and visual feedback by controlling the time of hitting the ball and repeating the play. About the Archery game, there is a higher demand for fine motor coordination, as fine adjustments are necessary to aim at the center of the target and obtain a higher score, in addition to coordination between members, as the two upper limbs are required simultaneously to center the target and shoot the arrow.

\section{Data processing and analysis}

The results of the performances in the selected games of the Wii console were tabulated in Excel and analyzed by appropriate statistics. In the Tennis 
training mode, the sum of the scores (i.e., performed strokes) that resulted from 20 attempts made on each participants' practice session was computed for further analysis. In Archery, the sum of the scores obtained from 12 shooting attempts of each game, with five game repetitions in each session of the participants, was computed for further analysis.

The definition regarding the moment of ceasing the practice sessions of the TD group occurred in function of the group performance in stabilizing their performances. The Tennis game in training mode served as the basis for the definition of stable performance. As shown in Figure 1, performance started to stabilize in session 5 through 7 . In this context, then, the TD group ended the practice and the pDCD group continued the sessions until whether we did or did not observed stability in their performance, as it occurred only in the session 10 through 11, as shown in Figure 1. For the purposes the practice protocol between groups, we adopted the same procedure for the Archery game, regardless of the stability of their performance in that game.

Friedman's test was used to compare the practice sessions in each group. Wilcoxon test was performed for comparing the first session of practice with the other practice sessions for TD (i.e., 2, 3, 4, 5, 6, 7) and pDCD (i.e., 2, 3, 4, 5, 6, 7, 8, 9, 10 and 11) groups. To compare the TD and $\mathrm{pDCD}$ groups in each practice session, the Mann-Whitney U Test was performed. The performance of the additional sessions (i.e., 8, 9, 10 and 11) of the pDCD group was contrasted with the performance of the last day of the TD group practice session (i.e., 7).

\section{RESULTS}

For the performance of the result in Tennis training mode, the results of the Friedman Test demonstrated significant differences between the practice sessions for each group, TD (X2 = 27.9, p <0.001); pDCD, (X2 = 69.8, $\mathrm{p}<0.001)$. The Wilcoxon a posteriori test showed significant differences between session 1 and sessions 4, 5, 6 and 7 of practice $(p=0.01)$ for the performance of the TD group. For the $\mathrm{pDCD}$ group, the results showed significant differences between session 1 and sessions 5, 6 7, 8, 9, 10 and 11 of practice ( $p>0.02)$. Mann-Whitney $U$ tests showed significant differences in the performance of Tennis training mode between groups (i.e., $\mathrm{pDCD} \times \mathrm{TD})$, in session $1(\mathrm{U}=11.5, \mathrm{p}=0.02)$, session $3(\mathrm{U}=8,0, \mathrm{p}=$ $0.01)$, session $4(U=4.5, p=0.001)$, session $5(U=5.0, p=0.002)$, session $6(\mathrm{U}=7.5, \mathrm{p}=0.006)$ and session $7(\mathrm{U}=12.0, \mathrm{p}=0.03)$. The performance of each Tennis game group training mode throughout the sessions is illustrated in Figure 1.

For the performance in the Archery game, the results of the Friedman test showed significant differences between the practice sessions for each group, $\mathrm{TD}(\mathrm{X} 2=28, \mathrm{p}<0.001)$; $\mathrm{pDCD}(\mathrm{X} 2=56.2$, $\mathrm{p}<0.001)$. The analysis with the Wilcoxon a posteriori test for the performance of the TD group 
showed significant differences between session 1 of practice and sessions 2, 3, 4, 6 and $7(\mathrm{p}=0.02)$. The results of the Wilcoxon a posteriori test for the performance of the $\mathrm{pDCD}$ group showed significant differences between session 1 of practice and sessions 2, 3, 4, 5, 6, 7, 8, 9, 10 and 11 of practice $(\mathrm{p}=0.02)$. Mann-Whitney $U$ tests showed significant differences in Archery performance between groups (i.e., $\mathrm{pDCD} \times \mathrm{TD}$ ), in session 1 $(\mathrm{U}=4.5, \mathrm{p}=0.003)$, session $2(\mathrm{U}=7.0, \mathrm{p}=0.008)$, session $4(\mathrm{U}=1.0, \mathrm{p}=$ $0.001)$, session $6(U=7.0, p=0.008)$, session $7(U=0.0, p=0.000)$ and session $8(\mathrm{U}=7.5, \mathrm{p}=0.01)$. The performance of each group in the practice of Archery game is shown in Figure 2.

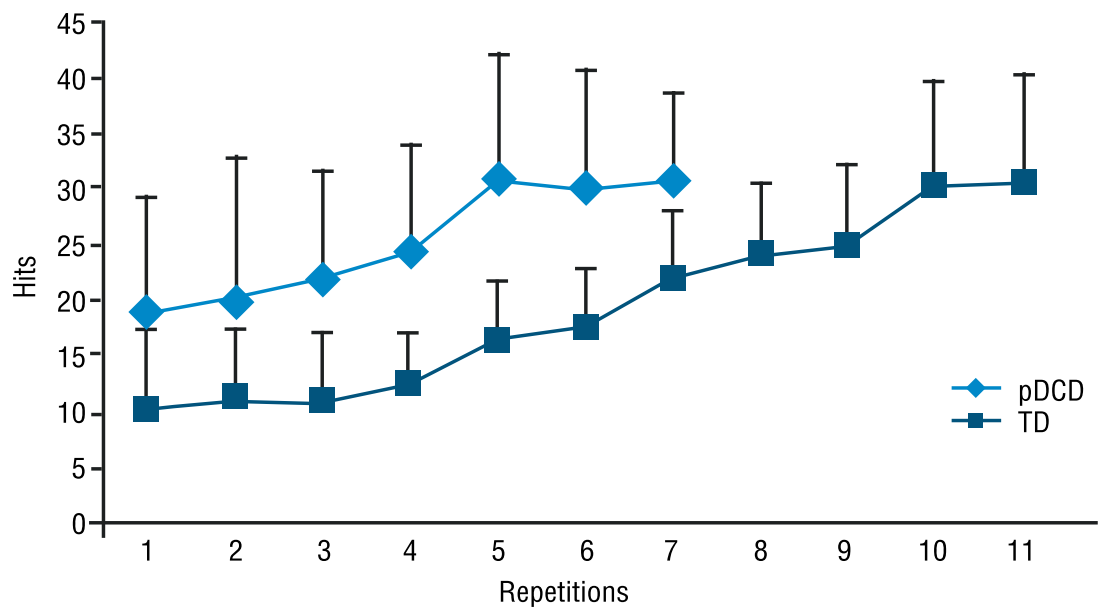

Figure 1. Average of hits in Tennis training mode game for the pDCD (probable of developmental coordination disorder) group for eleven practice sessions and TD (typical development) group for seven sessions.

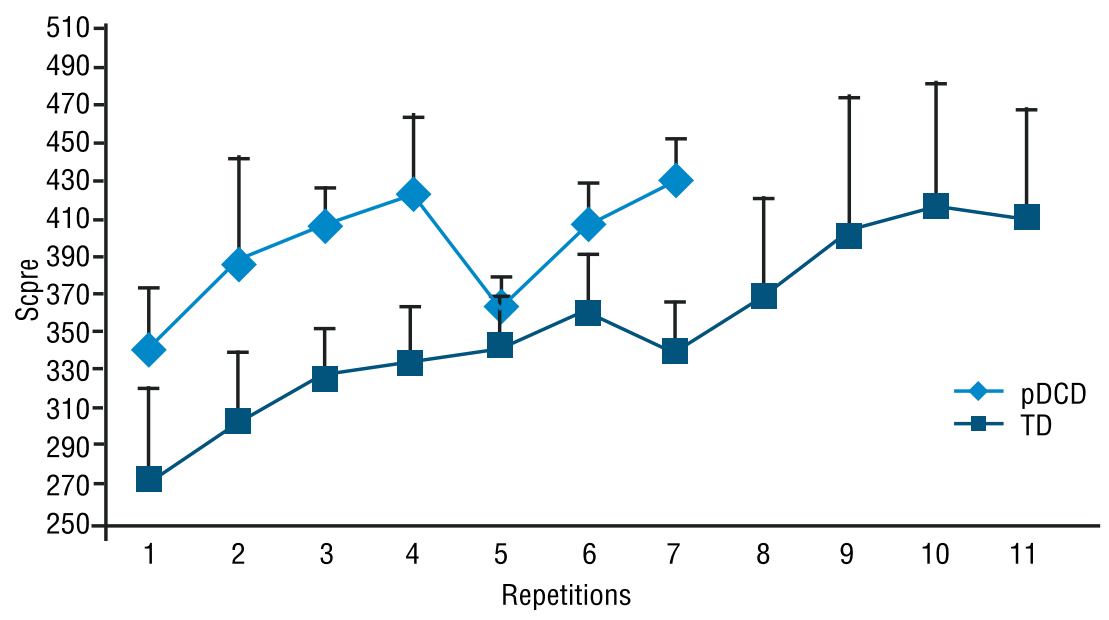

Figure 2. Average of score in the Archery game for $\mathrm{pDCD}$ (probable developmental coordination disorder) group for eleven practice sessions and TD (typical development) group for seven sessions.

\section{DISCUSSION}

The present study has two objectives. The first was to examine whether the practice based on the Wii console games would favor sensorimotor experiences with the potential to increase the performance of children 
with $\mathrm{pDCD}$. The results showed that children with $\mathrm{pDCD}$ improve their performance as a function of practice, but do not reach performance levels similar to those of their peers, both in the initial session and in the final practice session. The second objective was to examine whether a higher volume of practice (i.e., a higher number of sessions) of children with pDCD compared to their peers with TD would favor the performance of children with $\mathrm{pDCD}$. The results showed that children with $\mathrm{pDCD}$ have the potential to match their performance to the performance of children with TD due to a higher volume of practice. Children with DCD or pDCD have consistently lower performances than their peers with typical development ${ }^{15,16}$. The results of the present study replicate this fact. Taking the performance in session 1 of both groups as a reference point in the two games used (i.e., Tennis and Archery), the performance of children with pDCD was lower than their peers' performance with typical development. The cause of motor difficulties in children with DCD or $\mathrm{pDCD}$ is not clear yet. For some reason, these children are delayed in motor terms in relation to their corresponding pairs of similar age and gender.

Can delay in motor development be remedied via practice or training? Practice is an essential condition for the acquisition of motor skills. The practice of motor tasks by children with $\mathrm{pDCD}$ or DCD has the potential to improve the performance of these children in the practiced tasks. For instances, games based on active video games, such as those on the Wii console, can promote significant gains regarding muscle strength and general motor proficiency, which positively affects the execution of basic skill tasks ${ }^{17,18}$. However, the performance in acquiring these skills throughout practice or intervention is consistently inferior to the one of peers with typical development. The results of the present study regarding the effect of the practice by children with $\mathrm{pDCD}$ support the various studies presented in the literature.

The unique aspect of the present work was to seek to examine the effect of a higher volume of practice. In particular, it was offered more practice sessions to children with $\mathrm{pDCD}$ who consistently performed less than their peers with TD. The central idea was that if a larger volume of practice was offered (i.e., extra practice sessions) to the $\mathrm{pDCD}$ group after the TD group had stopped the practice, children with pDCD would reach the same level of performance of children with TD, particularly in Tennis training mode.

The results of the present study regarding Tennis training mode showed that children with TD significantly improved their performance from session 4 onwards. The performance of children with pDCD showed significant improvements, starting from session 5, having the performance of session 1 as a reference. Children with TD reached a performance plateau in session 5 followed by stability in game performance. Regarding the performance plateau by children with $\mathrm{pDCD}$, they reached the performance plateau only in session 10 . The performance plateaus of both groups are coincident on the ordinate axis, but the point on the abscissa 
axis to reach the plateaus between both groups differed by five sessions. Therefore, there is a substantial delay for children with pDCD to achieve the performance of children with TD.

Regarding the Archery game, children with TD significantly improved game performance between session 1 and the other sessions, excluding session 5 in which there was a small drop in performance. Similarly, the performance of children with $\mathrm{pDCD}$ was significantly different between session 1 and all other sessions. A slight drop in the performance of children with pDCD occurred in session 7. Similar to Tennis, children with pDCD required three extra sessions to reach the plateau and match the performance of their peers with TD.

Practice leads to an improvement in the performance of motor skills. Extra practice sessions or a higher volume of practice could give an advantage to those who receive these extra sessions. In the case of children with $\mathrm{pDCD}$, a higher volume of practice in relation to their peers with TD allowed them to equalize the conditions for the acquisition of the necessary skills to execute the game, but it did not give these children an advantage to increase the performance in relation to their peers with TD. The results of the present study indicate that children with $\mathrm{pDCD}$ need more opportunities to practice the motor task of interest. More opportunities for practice may allow them to develop their skills and abilities more fully for the task in order to establish relative equity in practice with respect to typical motor development.

One question that needs to be explored consistently is whether the number of practical sessions varies depending on the task. In the present study, the visual-motor integration component is very present in the task demand. Other types of tasks that require more emphasis on other skills and abilities may take a higher or lower amount of time for children to reach the same performance plateau as their peers with TD.

The results of the practice sessions in the present study had effects on the acquisition of the skill. Above all, children with $\mathrm{pDCD}$ presented the potential to match the performance of their TD peers, albeit later. These children are always at a motor disadvantage. The results of the present study show that to overcome a delay in the acquisition of motor skills, children with $\mathrm{pDCD}$ need a higher volume of practice than their peers with TD. This result reinforces the idea that children with $\mathrm{pDCD}$ are motor delayed not due to delayed motor development per se, but as a result of lack of practice and opportunities to explore the task and the environment. Providing an environment with more opportunities for these children can be an important strategy for them, particularly in the school environment.

\section{CONCLUSION}

Children with pDCD are always at a disadvantage when compared to their peers in various tasks that require visual-motor integration. The practice of these tasks leads to an improvement in the performance of both groups. 
However, children with $\mathrm{pDCD}$ take longer to achieve the performance that their peers with TD do. The results of the present study lead to the idea that the problem of motor difficulties by children with $\mathrm{pDCD}$ can be overcome or minimized by training and practicing tasks.

\section{COMPLIANCE WITH ETHICAL STANDARDS}

\section{Funding}

This research did not receive any specific grant from funding agencies in the public, commercial, or not-for-profit sectors.

\section{Ethical approval}

Ethical approval was obtained from the local Human Research Ethics Committee - Biosciences Institute, São Paulo State University - The protocol (no. 40187114.5.0000.5465) was written in accordance with the standards set by the Declaration of Helsinki.

\section{Conflict of interest statement}

The authors have no conflict of interests to declare.

\section{Author Contributions}

Conceived and designed the experiments: LSC, CYH, DTG. Performed the experiments: LSC, CSC. Analyzed the data: LSC, CYH. Contributed reagents/materials/analysis tools: LSC, CSC, CYH, DTG. Wrote the paper: LSC, CSC, CYH.

\section{REFERENCES}

1. Mandich AD, Polatajko HJ, Rodger S. Rites of passage: Understanding participation of children with developmental coordination disorder. Hum Mov Sci 2003;22(4-5):583-595.

2. Van Waelvelde H, De Weerdt W, De Cock P, Smits-Engelsman BCM. Aspects of the validity of the Movement Assessment Battery for Children. Hum Mov Sci 2004; 23 (1): 49-60.

3. Zwicker JG, Missiuna C, Harris SR, Boyd LA. Developmental coordination disorder: a review and update. Eur J Paediatr Neuro 2012, 16 (6): 573-581.

4. Schoemaker MM, Kalverboer AF. Social and Affective Problems of Children Who Are Clumsy: How Early Do" bey Begin? Adapt Phys Act Q1994; 11 (2): 140.

5. Piek JP, Bradbury GS, Elsley SC, Tate L. Motor Coordination and SocialEmotional Behaviour in Preschool-aged Children. Int J Disabil Dev Educ 2008; 55 (2):143-151.

6. Parush S, Yochman A, Cohen D, Gershon E. Relation of visual perception and visual-motor integration for clumsy children. Percept Mot Skills 1998; 86 (1): 291-295.

7. Wang TN, Tseng MH, Wilson BN, Hu FC. Functional performance of children with developmental coordination disorder at home and at school. Dev Med Child Neurol 2009; 51 (10): 817-825.

8. Adams IL, Steenbergen B, Lust JM, Smits-Engelsman BC. Motor imagery training for children with developmental coordination disorder-study protocol for a randomized controlled trial. BMC Neurol 2016; 16 (1): 1.

9. Pless M, Carlsson M, Sundelin C, Persson K. Effects of group motor skill intervention on five-to six-year-old children with developmental coordination disorder. Pediatr Phys Ther 2000; 12 (4): 183-189. 
10. Rizzo A, Kim GJ. A SWOT analysis of the field of virtual reality rehabilitation and therapy. Presence-Teleop Virt 2005; 14 (2): 119-146.

11. Levac D, Pierrynowski MR, Canestraro M, Gurr L, Leonard L, Neeley C. Exploring children's movement characteristics during virtual reality video game play. Hum Mov Sci 2010; 29 (6): 1023-1038.

12. Hammond J, Jones V, Hill EL, Green D, Male I. An investigation of the impact of regular use of the Wii Fit to improve motor and psychosocial outcomes in children with movement difficulties: a pilot study. Child Care Hlth Dev 2014; 40 (2): 165-175.

13. Henderson SE, Sugden DA, Barnett AL. The Movement Assessment Battery for Children. London: The Psychological Corporation; 2007.

14. American Psychiatric Association. DSM-5: Manual diagnóstico e estatístico de transtornos mentais. Porto Alegre: Artmed; 2014.

15. Deutsch JE, Borbely M, Filler J, Huhn K, Guarrera-Bowlby P. Use of a low-cost, commercially available gaming console (Wii) for rehabilitation of an adolescent with cerebral palsy. Phys Ther 2008; 88 (10): 1196-1207.

16. Schoemaker MM, Van der Wees M, Flapper B, Verheij-Jansen N, Scholten-Jaegers S, Geuze RH. Perceptual skills of children with developmental coordination disorder. Hum Mov Sci 2001; 20 (1): 111-133.

17. Bonney E, Jelsma D, Fergusson G, Smits-Engelsman B. Variable training does not lead to better motor learning compared to repetitive training in children with e without DCD when exposed to active video games. Res Dev Disabil 2017; 62: 124-136.

18. Bonney E, Fergusson G, Smits-Engelsman B. The efficacy of two activity-based interventions in adolescents with Developmental Coordination Disorder. Res Dev Disabil 2017; 71: 223-236.

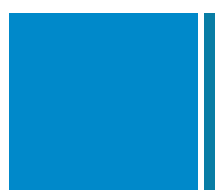

Corresponding author

Leonardo Soares de Carvalho

Rua Onze BNH, nº 8, Rio Claro

São Paulo - Brasil

E-mail: leonardo_90801@hotmail.com 